\title{
Carbohydrate structures in residual lignin-carbohydrate complexes of spruce and pine pulp
}

\author{
Christiane Laine*, Tarja Tamminen and Bo \\ Hortling
}

KCL, Espoo, Finland

${ }^{\star}$ Corresponding author.

P.O. Box 70, FIN-02151 Espoo, Finland

E-mail: christiane.laine@kcl.fi

\begin{abstract}
Residual lignin carbohydrate complexes (RLCC) were isolated enzymatically from spruce and pine pulp. The RLCCs contained 4.9-9.4\% carbohydrates, with an enrichment of galactose and arabinose compared to the original pulp samples. The main carbohydrate units present in all studied RLCCs were 4-substituted xylose, 4-, 3- and 3,6-substituted galactose, 4-substituted glucose and 4 and 4,6-substituted mannose. These units were assigned to carbohydrate residues of xylan, 1,4- and 1,3/ 6-linked galactan, cellulose and glucomannan.

RLCCs of surface material and the inner part of spruce kraft pulp fiber were compared to obtain information on the heterogeneity of layers of the fiber wall. The 1,4linked galactan was the major galactan in RLCC of fiber surface material of spruce kraft pulp. Towards the inner part of the fiber, the proportion of 1,3/6-linked galactan increased relative to $1,4-$ linked galactan. This finding is presented for the first time. 1,3/6-Linked galactan structures are suggested to have a role in restricting lignin removal from the secondary fiber wall.

RLCCs of three different alkaline pine pulps were studied before and after oxygen delignification to evaluate differences resulting from the cooking method. The pulps were conventional kraft pine pulp (PCK), a polysulfide/ anthraquinone pine pulp (PPSAQ) and a soda/anthraquinone pine pulp (PSoAQ); all were cooked to approximately kappa number 30 . Small differences were found in the carbohydrate structures of the unbleached pulps. The study indicated that the RLCC of unbleached PSoAQ pulp contained longer oligomeric carbohydrate chains and less branched 1,3/6-linked galactan residues than the RLCCs of unbleached PCK and PPSAQ pulps. The RLCC of the unbleached PSoAQ also contained more 1,4-linked glucose units suggesting a greater number of linkages of lignin to cellulose in the PSoAQ pulp than in the other two pulps. All RLCCs of oxygen-delignified pulps had more non-reducing ends and less 1,3/ 6-linked galactan than the corresponding RLCCs of the unbleached pulps. The RLCC of the oxygen-delignified PSoAQ pulp had a higher ratio of 1,4-galactan to 1,3/6linked galactan and shorter xylan residues than the RLCCs of oxygen-delignified PCK and PPSAQ pulps.
\end{abstract}

Keywords: chemical pulp; fiber; fines; lignin-carbohydrate complex; Norway spruce; oxygen delignification;
Picea abies; Pinus sylvestris; polysaccharide; residual lignin; Scots pine; structural analysis.

\section{Introduction}

The composition of unbleached pulps is well known, consisting mainly of cellulose and to a smaller extent hemicelluloses and residual lignin. However, the isolation of lignin using enzymatic hydrolysis has shown that the composition of the carbohydrate residues remaining in lignin samples differs considerably from that in the pulp (Hortling et al. 2001). It is assumed that these oligomeric carbohydrate residues originate from polysaccharides linked to the lignin in pulps.

The enrichment of galactans has been reported in enzymatically-isolated lignins and enzyme-treated lignin carbohydrate complexes (LCCs). The enzyme preparations typically applied were mixtures of cellulose- and hemicellulose-hydrolyzing enzymes. The enrichment of galactose in enzymatically-isolated residual lignin of loblolly kraft pulp (Pinus taeda) was reported in 1981 (Yamasaki et al. 1981). Lignin from ball-milled loblolly pine wood - isolated using cellulolytic enzymes (MWEL) - has been shown to contain oligomeric chains of mainly 1,4linked galactose, glucose, mannose and xylose units. The corresponding MWEL of red pine compression wood was clearly enriched in 1,4-linked galactan (more than $60 \%$ of the carbohydrate residues), while the proportion in the MWEL of loblolly pine was about $14 \%$ (Minor 1982). 1,4- and 1,3-linked galactan have been found in enzymatically-isolated residual lignin from unbleached loblolly pine kraft pulp (Minor 1986). It has been shown that for a high-yield loblolly pine kraft pulp there is an enrichment of 1,4-linked galactan in lignin enzymatically isolated from a middle-lamellae-rich fraction compared to lignin of the secondary wall (Minor 1991). Enzymaticallytreated LCC from black spruce (Picea mariana) was slightly enriched in galactose (Eriksson et al. 1980). There was also an enrichment of 1,4-linked galactan in enzymatically-treated LCC from Norway spruce (Picea abies; Iversen 1985) and akamatsu wood (Pinus densiflora Sieb. and Zucc.; Watanabe 1989), enzymatically-treated soluble pine kraft lignin (Pinus radiata; Iversen and Westermark 1985) and enzymatically-isolated residual lignin from pine kraft pulp (Pinus sylvestris; Iversen and Wännström 1986). 1,3- and 1,4-linked galactan has also been found in pine kraft cooking liquors (Pinus sylvestris; Vikkula et al. 1997) and filtrates of oxygen delignification stages (Pinus sylvestris; Laine and Tamminen 2002). Cooking liquors of reaction wood contained relatively more 1,4-linked galactan than the corresponding cooking liquors of normal wood (Vikkula et al. 1997). The enrichment of galactose among the carbohydrate components in RLCCs is of interest and it has been suggested that 
galactans hinder the removal of lignin during delignification (Hortling et al. 2001). In addition, the enhanced bleachability of pulps treated with specific galactanases has demonstrated the involvement of galactans in structures that cause problems during bleaching (Tamminen et al. 1999). The additional presence of arabinan in enzymatically-isolated lignin reported in the cited literature has indicated an enrichment of arabinan next to galactan in the lignin.

Several methods are available to isolate residual lignin from pulp. The major methods include acidolytic and enzymatic hydrolysis (Tamminen and Hortling 1999) and a procedure combining both enzymatic and acid hydrolysis (Argyropoulos et al. 2002). In the present study, a procedure using enzymatic hydrolysis was chosen. This method was suitable for the purpose, because it yielded residual lignin-carbohydrate complexes (RLCCs) instead of pure lignin. Cellulase and hemicellulase enzymes cannot act in close proximity to lignin due to their steric requirements, and therefore oligomeric residues of carbohydrates are left, bound to the lignin. The bonds between carbohydrates and lignin would be partly cleaved in procedures including acid hydrolysis. In addition, a high yield of residual lignin is obtained in enzymatic isolation procedures (Hortling and Tamminen 2001; Jääskeläinen et al. 2003).

An insufficient activity of 1,4- $\beta$-D-galactanase in enzyme preparations from fungal sources has been suggested to cause the enrichment of galactose-containing residues in enzymatically-isolated lignin (Iversen et al. 1987). Despite this possibly overly large proportion of galactose in the isolated lignin, the linkage between galactans and lignin is proved by the very presence of galactose in the samples. The galactan-lignin linkages have been further supported by the enrichment of galactose in high molar mass residual kraft lignin obtained by preparative gel permeation chromatography (Hortling et al. 2001). The authors also showed that there were linkages between lignin and the other carbohydrate residues.

RLCCs of spruce pulp were studied, as well as those of different pulp fractions following gentle refining. The fractions consisted of peeled fibers and material enriched in surface material separated as fines. The aim was to compare the surface and inner layer of spruce kraft pulp fibers.

Different alkaline pine pulps were studied. The bleachability as well as yield and carbohydrate composition of three alkaline pine pulps - a conventional kraft pulp (PCK), a polysulfide/anthraquinone pulp (PPSAQ) and a soda/anthraquinone pulp (PSoAQ) - cooked to the same kappa number level were studied recently (Hortling et al. 2000). The bleachability of the pulps decreased in the order PCK, PPSAQ and PSoAQ. A study on the structure of the residual lignin did not reveal a clear correlation with the different bleachabilities (Tamminen and Hortling 2001). One possibility is that the carbohydrate structures linked to the residual lignin differed between the pulps. RLCCs were studied before and after oxygen-delignification. To our knowledge, comparison of carbohydrate structures connected to residual lignin in different unbleached pulps and, in general, in oxygen-delignified pulp has not been performed before.

The methods applied in this work included linkage analysis and analysis of reducing ends of carbohydrate residues bound to residual lignin. Methylation analysis was performed as linkage analysis. Information on the substituted hydroxyl groups of the monosaccharide building blocks was obtained except for the glycosidic hydroxyl group (Laine et al. 2002). Therefore, the methylation analysis applied did not distinguish reducing end units from the other units in the main or side-chains. The reducing ends were analyzed separately using a reduction step, methanolysis and subsequent analysis of the methyl glycosides and alditols obtained. The information acquired was used in combination with knowledge relating to the structure of hemicelluloses and cellulose to draw conclusions about the structure of the carbohydrate residues.

Special emphasis was put on the structure of ligninbound galactans in the different samples. Two separate galactans are known in wood, a mostly linear $\beta-1,4-$ linked galactan with substitution mainly at position 6 , and a highly branched $\beta$-1,3-linked galactan with frequent substitution at position 6 . The structures of the galactans involved and their distribution throughout the fiber wall have to be known so that methods can be devised for their cleavage.

\section{Materials and methods}

\section{Pulp preparation}

Spruce chips (Picea abies) were cooked using the kraft process with a final temperature of $170^{\circ} \mathrm{C}$ in a conventional batch reactor

Table 1 Pulping conditions and properties of the different pulps.

\begin{tabular}{|c|c|c|c|c|c|c|}
\hline Cooking method & $\begin{array}{l}\text { Eff. alkali } \\
\left(\mathrm{mol} \mathrm{kg}^{-1}\right)\end{array}$ & $\begin{array}{l}\text { Sulfidity } \\
\text { (\%) }\end{array}$ & $\mathrm{H}$-factor & $\begin{array}{l}\text { Total yield } \\
(\%)\end{array}$ & $\begin{array}{l}\text { Kappa } \\
\text { number }\end{array}$ & $\begin{array}{l}\text { Viscosity } \\
\left(\mathrm{ml} \mathrm{g}^{-1}\right)\end{array}$ \\
\hline $\begin{array}{l}\text { Spruce conventional } \\
\text { kraft } 1 \text { (SCK1) }\end{array}$ & 4.5 & 35 & & & 35.7 & 1290 \\
\hline $\begin{array}{l}\text { Spruce conventional } \\
\text { kraft } 2 \text { (SCK2) }\end{array}$ & 4.5 & 35 & & & 37.3 & 1260 \\
\hline $\begin{array}{l}\text { Pine conventional } \\
\text { kraft (PCK) }\end{array}$ & 4.5 & 35 & 1750 & 47 & 31 & 1270 \\
\hline $\begin{array}{l}\text { Pine polysulfide-AQ } \\
\text { (PPSAQ) }\end{array}$ & 5.0 & 14 & 1000 & 51 & 33 & 1180 \\
\hline $\begin{array}{l}\text { Pine soda-AQ } \\
(\mathrm{PSo} A Q)^{\star}\end{array}$ & 5.5 & 0 & 1900 & 47 & 30 & 930 \\
\hline
\end{tabular}

*The anthraquinone (AQ) charge was $2 \%$ both in PSoAQ and PPSAQ cooking and the PS charge was $15 \mathrm{~g} \mathrm{~kg}^{-1}$ for PPSAQ cooking. 
(liquor-to-wood ratio 3.5:1). Two parallel pulps were prepared from the same batch of spruce chips (Table 1). SCK1 (1.3 kg) was refined in a Voith Sulzer laboratory refiner at $4 \%$ consistency with a specific edge load of $1.0 \mathrm{~W} \mathrm{~s} \mathrm{~m}^{-1}$. The refined pulp was fractionated using a filter with a 200 mesh wire into fines ( $4.5 \%$ of the refined pulp) and fibers as described previously (Liitiä et al. 2000a).

Three chemical pulps were prepared from pine wood chips (Pinus sylvestris) from southeastern Finland. The cooking conditions (Table 1) were selected to obtain kappa numbers close to 30 for the different pulps. The unbleached pine pulps were oxygen-delignified in a Quantum Mark reactor at $10 \%$ consistency and $90^{\circ} \mathrm{C}$ for $1 \mathrm{~h}$ at 8 bar oxygen pressure. The $\mathrm{NaOH}$ charge was $2.52 \%$ for PCK, $3.10 \%$ for PPSAQ and $2.65 \%$ for PSoAQ. $0.5 \% \mathrm{MgSO}_{4}$ was added and the yield for all three pulps was $98 \%$. The resulting kappa numbers were 17.2 for PCK/O, 18.7 for PPSAQ/O and 16.3 for PSoAQ/O, which were close to the targeted $50 \%$ delignification (Hortling et al. 2000).

\section{Isolation of RLCCs}

The RLCCs were isolated from the pulps and the pulp fractions by enzymatic hydrolysis with the cellulolytic enzyme preparations Econase CEP (Röhm Enzymes) and Novozym 188 (Novo Nordisk), followed by protease purification using Subtilisine (Sigma). Two fractions were obtained: the insoluble residue at the $\mathrm{pH}$ of the purification (pH 9.5; prois) and the precipitate after $\mathrm{pH}$ adjustment of the solution to 2.5 (proRL; Tamminen and Hortling 1999). Further fractionation of the SCK1 prois sample obtained was performed by dissolution in $0.5 \mathrm{M} \mathrm{NaOH}$. The fraction insoluble in $0.5 \mathrm{M} \mathrm{NaOH}$ is referred to as proisis and the fraction soluble in $0.5 \mathrm{M} \mathrm{NaOH}$ obtained after precipitation at $\mathrm{pH} 2.5$ proissP.

The content of protein impurities in the RLCCs resulting from the enzymatic isolation was calculated from the nitrogen content (Analytical Laboratories, Lindlar, Germany) multiplied by 6.25 . It accounted for $3.5-5 \%$ for the spruce pulp samples and $3.7-4.0 \%$ and $8.5-9.0 \%$ for the proRL fractions of the unbleached and oxygen-delignified pine pulps, respectively. These protein impurities are known to contain 10\% carbohydrates, consisting of $85 \%$ mannose, $8.5 \%$ glucose and $6.5 \%$ galactose (Tamminen and Hortling 1999).

\section{Methylation}

Methylation was performed using a modification of the method of Ciucane and Kerek (1984) as published recently (Laine et al. 2002): About $20 \mathrm{mg}$ ground sodium hydroxide and $0.1 \mathrm{ml}$ methyl iodide were added to $20 \mathrm{mg} \mathrm{RLCC}$ in $0.5 \mathrm{ml}$ dimethylsulfoxide. The sample was kept for $30 \mathrm{~min}$ in an ultrasonic bath at room temperature. Water was then added, the $\mathrm{pH}$ was adjusted to 2.5 and the sample was centrifuged at $6000 \mathrm{~g}$ for $20 \mathrm{~min}$. The residue was freeze-dried. A second methylation cycle similar to the first was carried out for the spruce pulp samples. A third methylation cycle was performed only for the pine pulp samples. The progress of methylation of the RLCCs from pine pulp samples was estimated semiquantitatively by monitoring the peaks at $3400 \mathrm{~cm}^{-1}$ (decrease in hydroxyl group content) and $2930 \mathrm{~cm}^{-1}$ (increase in methyl group content) in FTIR spectra. The FTIR spectra were recorded from $\mathrm{KBr}$ pellets using a Nicolet Nexus 870 FTIR. After the methylation, acid methanolysis and silylation were performed. Identification and quantification were carried out using GC/MS.

\section{Analysis of reducing ends}

Reduction of selected RLCC samples was performed by adding $20 \mathrm{mg} \mathrm{NaBH}_{4}$ to $50 \mathrm{mg} \mathrm{RLCC}$ in $2 \mathrm{ml} 0.1 \mathrm{M} \mathrm{NaOH}$ and stirring

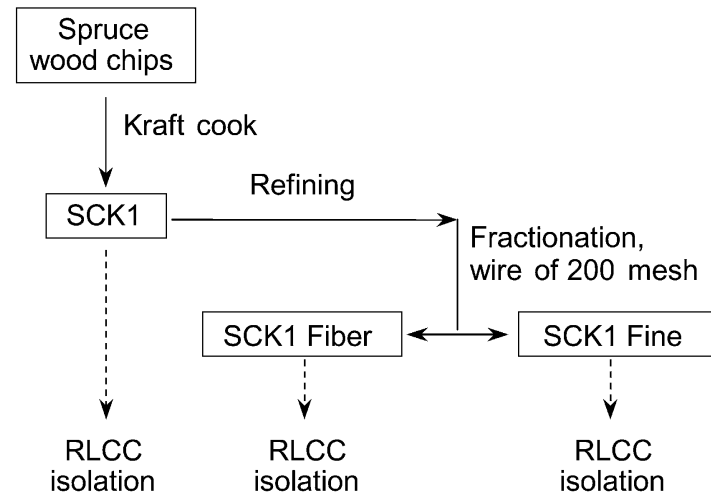

Figure 1 Preparation of the spruce kraft pulp, peeled fibers (Fiber) and material enriched in surface material (Fine).

overnight at room temperature. The RLCC was precipitated by regulating the $\mathrm{pH}$ to 2.5 using $1 \mathrm{M} \mathrm{HCl}$. The precipitate was obtained using centrifugation (see above) and freeze-drying. Acid methanolysis was performed directly on half of the sample as described above; the other half was reduced a second time and then acid methanolysis was performed. Identification and quantification were carried out using GC/MS as described before for the methylation analysis (Laine et al. 2002), with the exception that inositol was used as internal standard instead of sorbitol.

\section{Other analytical methods}

Kappa number (Scandinavian Standard SCAN-C 1:77) and viscosity (Scandinavian Standard SCAN-CM 15:99) were determined according to standard procedures. Klason and acid-soluble lignin were determined after acid hydrolysis (Browning 1967). The carbohydrate content and composition were determined using acid hydrolysis and high performance anion exchange chromatography with pulse amperometric detection (HPAEC/PAD) as described earlier (Hausalo 1995). The content of hexenuronic acid groups was determined for the hydrolyzate of the enzymatic hydrolysis before precipitation of lignin using HPAEC/PAD (Tenkanen et al. 1995). Uronic acids were determined using acid methanolysis (Sundberg et al. 1996).

The theoretical lignin content of the pulp samples was calculated from the kappa number using the factor 0.15 . The "lignin kappa number" of the pine pulps was calculated from the determined kappa number by subtraction of the product of the content of hexenuronic acid groups and the factor $0.086 \mathrm{~kg} \mathrm{mmol}^{-1}$ (Li and Gellerstedt 1997).

\section{Results and discussion}

\section{Pulps and pulp fractions}

Fines were liberated from laboratory-cooked spruce kraft pulp SCK1 using a "surface-active" refining of the pulp. After the refining, fractionation delivered the fines fractions enriched in fiber surface material and the fiber fraction (Figure 1).

The three alkaline pine pulps PCK, PPSAQ and PSoAQ with a kappa number close to 30 differed in viscosity (Table 1) and carbohydrate composition (Table 2). As expected, a higher yield was obtained for the PPSAQ pulp (51\%) compared to the PCK and PSoAQ pulps. The amount of glucomannan was higher in the PPSAQ pulp than in the PCK and PSoAQ pulps due to the stabilizing 
Table 2 Carbohydrate composition given as monosaccharides and hexenuronic acid content in the unbleached and oxygen-delignified pulps.

\begin{tabular}{lcccccrc}
\hline Pulp & $\begin{array}{c}\text { Total neutral } \\
\text { carbohydrates } \\
(\mathrm{mg} / 100 \mathrm{mg})\end{array}$ & $\begin{array}{c}\text { Ara } \\
(\%)\end{array}$ & $\begin{array}{c}\text { Gal } \\
(\%)\end{array}$ & $\begin{array}{c}\text { Glu } \\
(\%)\end{array}$ & $\begin{array}{c}\text { Xyl } \\
(\%)\end{array}$ & $\begin{array}{c}\text { Man } \\
(\%)\end{array}$ & $\begin{array}{c}\text { Hexenuronic acid } \\
\text { groups }\left(\mathrm{mmol} \mathrm{kg}^{-1}\right)\end{array}$ \\
\hline SCK1 & 95.5 & 0.8 & 0.3 & 83 & 9.1 & 6.5 & \\
PCK & 91.4 & 1.0 & 0.4 & 83 & 9.0 & 7.0 & 28 \\
PPSAQ & 90.4 & 0.7 & 0.6 & 79 & 7.5 & 12.5 & 24 \\
PSOAQ & 85.2 & 0.5 & $+^{*}$ & 83 & 7.6 & 8.7 & 29 \\
PCK/O & 89.9 & 0.7 & $+^{*}$ & 84 & 8.7 & 6.7 & 26 \\
PPSAQ/O & 94.3 & 0.6 & 0.5 & 81 & 6.9 & 11.3 & 13 \\
PSOAQ/O & 97.2 & 0.4 & 0.3 & 84 & 7.2 & 8.3 & 15 \\
\hline
\end{tabular}

${ }^{\star}$ Detected but below determination limit of $0.3 \mathrm{mg}$ galactose $/ 100 \mathrm{mg}$ pulp.

Ara, arabinose; Gal, galactose; Glu, glucose; Xyl, xylose; Man, mannose.

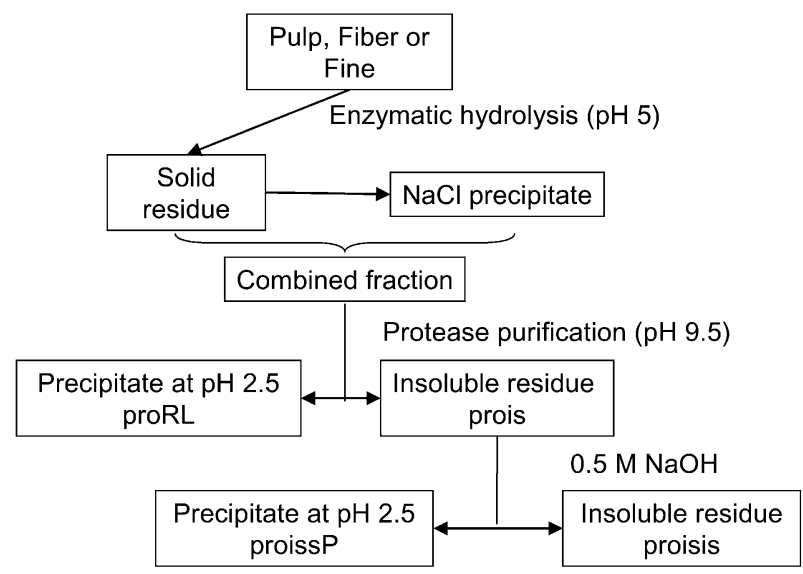

Figure 2 Isolation and purification of RLCCs.

conditions of the pulping method. The PSoAQ pulp contained less hexenuronic acid groups than the other two pulps. The unbleached as well as the oxygen-delignified pulp were studied. The carbohydrate content and composition did not change significantly in the oxygen delignification (Table 2).

\section{Isolation of RLCCs}

RLCC samples were isolated according to the experimental part and Figure 2. The yield and the purity with respect to the residual lignin are shown in Table 3. For the spruce pulps, the yield of the lignin isolation - taking into account the insoluble residue at the $\mathrm{pH}$ of the purification ( $\mathrm{pH}$ 9.5) (prois) and the precipitate after $\mathrm{pH}$ adjustment to 2.5 (proRL) - was good with $87-93 \%$ calculated as pure lignin.

Because of problems associated with the linkage analysis of carbohydrate residues in the sparingly soluble prois fractions of the spruce pulp (see below), only the RLCC fraction soluble at $\mathrm{pH} 9.5$ (proRL) was subjected to detailed analysis for the pine pulps. This RLCC fraction contained the major portion of residual lignin in the unbleached and oxygen-delignified pulps (Table 3). As a basis for the calculation of the theoretical lignin content of the pine pulps, the kappa number was corrected to take into account the contribution of hexenuronic acid groups. This was done to eliminate the contribution of the different quantities of hexenuronic acid groups to the kappa number (Tamminen and Hortling 2001). The yields of RLCCs were lower than earlier published yields for the

Table 3 Yield and purity of lignin in the RLCCs.

\begin{tabular}{|c|c|c|c|c|c|c|}
\hline & \multicolumn{2}{|c|}{ proRL } & \multicolumn{2}{|c|}{ prois } & \multirow{2}{*}{$\begin{array}{c}\text { Total residual } \\
\text { lignin yield }{ }^{1} \\
(\%)\end{array}$} & \multirow{2}{*}{$\begin{array}{l}\text { Theoretical } \\
\text { lignin content } \\
\% \text { of sample }\end{array}$} \\
\hline & $\begin{array}{c}\text { Yield }^{1} \\
(\%)\end{array}$ & $\begin{array}{c}\text { Purity }{ }^{2} \\
\text { (\%) }\end{array}$ & $\begin{array}{c}\text { Yield }^{1} \\
(\%)\end{array}$ & $\begin{array}{c}\text { Purity }{ }^{2} \\
\text { (\%) }\end{array}$ & & \\
\hline SCK1 & 47 & 90 & 46 & 91 & 93 & $5.4^{4}$ \\
\hline SCK2 & 55 & 93 & 37 & 93 & 92 & $5.6^{4}$ \\
\hline SCK Fiber & 45 & 93 & 43 & 93 & 87 & $5.4^{4}$ \\
\hline SCK Fines & 25 & 90 & $107^{3}$ & & & $11.0^{5}$ \\
\hline PCK & 77 & 89 & & & & $4.4^{6}$ \\
\hline PPSAQ & 63 & 87 & & & & $4.7^{6}$ \\
\hline PSoAQ & 66 & 87 & & & & $4.6^{6}$ \\
\hline $\mathrm{PCK} / \mathrm{O}$ & 83 & 83 & & & & $2.2^{6}$ \\
\hline PPSAQ/O & 86 & 82 & & & & $2.5^{6}$ \\
\hline PSoAQ/O & 94 & 82 & & & & $2.3^{6}$ \\
\hline
\end{tabular}

Lignin purity is taken into account.

${ }^{2}$ Lignin purity $=100 \%-$ protein $(\%)$ - carbohydrates (\%).

${ }^{3}$ The sample contains most probably crystalline cellulose, see text.

${ }^{4}$ Calculated from the kappa number.

${ }^{5}$ Klason and acid-soluble lignin.

${ }^{6}$ Calculated from the kappa number corrected for the contribution of hexenuronic acid groups. 
Table 4 Carbohydrate content and composition in the RLCC samples analyzed after acid hydrolysis, mg/100 mg. No correction for mannose present in protein residues was performed.

\begin{tabular}{|c|c|c|c|c|c|c|}
\hline Sample (mg/100 mg) & Total & Ara & Gal & Glu & Xyl & Man \\
\hline SCK1 proRL & 7.0 & 0.4 & 1.9 & 1.2 & 1.6 & 1.9 \\
\hline SCK1 prois & 6.9 & 0.3 & 2.7 & 1.0 & 1.3 & 1.6 \\
\hline SCK2 proRL & 7.6 & 0.4 & 2.2 & 1.2 & 1.6 & 2.2 \\
\hline SCK2 prois & 7.9 & 0.5 & 3.3 & 1.2 & 1.3 & 1.6 \\
\hline SCK Fiber proRL & 7.5 & 0.4 & 1.9 & 1.3 & 1.8 & 2.2 \\
\hline SCK Fiber prois & 6.9 & 0.3 & 2.6 & 1.0 & 1.3 & 1.6 \\
\hline SCK Fine proRL & 5.9 & 0.6 & 1.4 & 1.0 & 1.4 & 1.5 \\
\hline SCK Fine prois & 4.9 & 0.8 & 1.7 & $0.7^{\star}$ & 0.9 & 0.8 \\
\hline PCK proRL & 7.5 & 0.4 & 2.1 & 1.2 & 1.6 & 2.2 \\
\hline PPSAQ proRL & 9.4 & 0.4 & 2.7 & 1.6 & 1.3 & 3.4 \\
\hline PSoAQ proRL & 8.3 & 0.4 & 2.1 & 1.6 & 1.4 & 2.8 \\
\hline PCK/O proRL & 7.7 & 0.5 & 1.4 & 1.4 & 1.6 & 2.8 \\
\hline PPSAQ/O proRL & 9.0 & 0.4 & 2.1 & 1.6 & 1.2 & 3.7 \\
\hline PSoAQ/O proRL & 8.3 & 0.4 & 1.3 & 1.7 & 1.4 & 3.4 \\
\hline
\end{tabular}

${ }^{*}$ Cellulose is not detected under the applied acid hydrolysis conditions, which leads to underestimation of glucose content for this sample (see text).

For abbreviations of sugars, see legend to Table 2.

unbleached pulps (Tamminen and Hortling 2001) because the earlier data also included sparingly alkalisoluble RLCC fraction prois. Still, the lignin in the RLCC samples studied here represented between $63 \%$ and $94 \%$ of the theoretical lignin content. This was considered as sufficient to deliver representative results in the following part.

The prois fraction of SCK1 was further fractionated into a sparingly alkali-soluble proiss $P$ fraction and an alkaliinsoluble proisis fraction. The yields of the fractions turned out to be approximately equal.

\section{Carbohydrate composition in RLCCs}

The RLCCs contained with 4.9 to 9.4 mg carbohydrates/ $100 \mathrm{mg}$ sample as determined after acid hydrolysis, which are typical amounts of carbohydrate residues (Table 4). O-methyl glucuronic acid, glucuronic acid and galacturonic acid were not detected in significant amounts $(<0.1 \mathrm{mg} / 100 \mathrm{mg})$. The values were not corrected for the share of carbohydrates in the protein residues. The correction would only significantly affect the mannose content, reducing it by $0.2-0.4 \mathrm{mg} / 100 \mathrm{mg}$ and $0.8-0.9 \mathrm{mg} / 100 \mathrm{mg}$ for the unbleached pulps (including spruce pulp fractions) and oxygen-delignified pulps, respectively. The correction was not made because the structural analysis described below was carried out on the sample, including the protein residue. Mannose and galactose were the major carbohydrate components in the RLCCs of the unbleached pulps in agreement with earlier results (Yamasaki et al. 1981; Iversen and Wännström 1986; Minor 1986; Hortling et al. 2001). The results confirm those from the earlier studies discussed in the introduction which indicated an enrichment of galactose in enzymatically-isolated residual lignins. The proportion of galactose of all carbohydrates in the unbleached pulps was much lower with $0.3-0.6 \%$ compared to $25-40 \%$ in the RLCCs. During oxygen delignification the amount of galactose in the RLCCs decreased and the corresponding quantities in the oxygen-delignified pulps and the corresponding RLCCs were between $<0.3-0.6 \%$ and $16-23 \%$, respectively. More galactose was found in the prois compared to the pro RL fractions. The high mannose content in the RLCC from PPSAQ reflected the higher mannose content of the corresponding pulp (Table 2). The carbohydrates in the proissP and proisis fractions of SCK1 were not determined. Results of earlier work suggested that the proisis fraction of the SCK1 and SCK1 Fine samples contained significant amounts of cellulose (Liitiä et al. 2000b).

\section{Carbohydrate structure of RLCCs}

The structure of the carbohydrates connected to lignin in the RLCCs was studied using methylation analysis. For the spruce pulp samples, the degree of methylation of proRL and prois fractions after two repeated methylations was in most cases between 53 and $74 \%$ (Table 5), the only exception being $20 \%$ for the prois fraction of SCK1 Fine. The pine pulp samples were methylated a third time delivering a degree of methylation higher than $90 \%$ in most cases. Obviously, the third methylation cycle improved the results. On the other hand, isolated galactoglucomannan samples (Willör et al. 2003) and carbohydrates in large molecular fractions of bleaching effluents (Laine and Tamminen 2002) have been easily methylated using a single methylation step in earlier studies. This indicates that the close contact with lignin lowers the reactivity of the carbohydrate residues. The extreme unreactivity of the SCK1 Fine prois sample was possibly due to the presence of cellulose in the RLCC (Liitiä et al. 2000b). In the primary fiber wall, cellulose fibril orientation is less ordered than in the secondary wall. It is suggested that lignin partly surrounds cellulose fibrils on the fiber surface. This would mean that cellulolytic enzymes would not hydrolyze the cellulose completely in the fines for steric reasons, while they hydrolyze the major part of the crystalline cellulose - cellulose of the secondary wall - present in pulp fibers. This hypothesis is further supported by Minor's suggestion in his work (1982) that microcrystalline cellulose is present in enzymatically-isolated MWEL of loblolly pine. He based his conclusion on the fact that glucose units did not react in 
Table 5 Non-methylated units of all identified carbohydrate structural units in RLCCs in mol\%, ratio of 1,4 to 1,3/6-linked galactan, branching in 1,3/6 linked galactan (given as proportion of branched units) and share of non-reducing ends (total/methylated units or share within individual monosaccharide).

\begin{tabular}{|c|c|c|c|c|c|c|c|c|}
\hline \multirow[t]{2}{*}{ RLCC } & \multirow{2}{*}{$\begin{array}{c}\text { Not } \\
\text { methylated } \\
(\mathrm{mol} \%)\end{array}$} & \multirow{2}{*}{$\begin{array}{c}1,4 \text { to } \\
1,3 / 6- \\
\text { linked } \\
\text { galactan }\end{array}$} & \multirow{2}{*}{$\begin{array}{c}\text { Branching in } \\
1,3 / 6 \text { linked } \\
\text { galactan } \\
\text { (mol\%) }\end{array}$} & \multicolumn{5}{|c|}{ Non-reducing end groups (mol\%) } \\
\hline & & & & Total & Xyl & Gal & Glu & Man \\
\hline SCK1 proRL & 26 & 0.9 & 36 & 23 & 31 & 16 & 25 & 22 \\
\hline SCK1 prois & 42 & 1.5 & 25 & 15 & & & & \\
\hline SCK1 Fiber proRL & 47 & 0.6 & 37 & 22 & & & & \\
\hline SCK1 Fine proRL & 39 & 1.3 & 35 & 19 & & & & \\
\hline PCK proRL & 9 & 1.4 & 41 & 18 & 22 & 15 & 15 & 20 \\
\hline PPSAQ proRL & 7 & 1.4 & 31 & 18 & 19 & 18 & 15 & 21 \\
\hline PSoAQ proRL & 8 & 1.5 & 17 & 14 & 15 & 13 & 9 & 19 \\
\hline PCK/O proRL & 17 & 1.9 & 35 & 22 & 22 & 17 & 21 & 28 \\
\hline PPSAQ/O proRL & 4 & 2.0 & 27 & 21 & 22 & 15 & 20 & 26 \\
\hline PSoAQ/O proRL & 7 & 2.4 & 23 & 22 & 27 & 14 & 21 & 27 \\
\hline
\end{tabular}

For abbreviations of sugars, see legend to Table 2 .

the methylation analysis and were not degraded by the mixture of cellulolytic enzymes applied.

In all cases, non-methylated carbohydrate residues also included hemicellulose residues. The reason for the unreactivity might be that even hemicelluloses are partly covered by lignin.

Analysis showed that repeated methylation was not sufficient for complete methylation. Further methylation of the spruce pulp samples was not possible due to a shortage of isolated RLCCs. The pine RLCC samples were methylated a third time. Three cycles were estimated as optimal even though approximately $10 \%$ of the carbohydrate residues were still unmethylated. However, further methylation cycles were estimated to improve the degree of methylation only slightly. Simultaneously a loss of the sample as a result of the procedure restricted the number of methylation cycles.

The degree of methylation was estimated to be high enough to deliver reasonable results for the SCK1 proRL samples, although a higher degree would have given more reliable results. The prois fraction was analyzed in more detail for the SCK1 pulp sample only, as the degree of methylation of the carbohydrate residues in that RLCC was at an acceptable level (60\%), in contrast to the corresponding RLCC of the SCK1 Fine sample. The degree of methylation of the pine pulp samples was satisfying as the third methylation cycle improved the results.

The structural distribution of the identified carbohydrate units showed that the RLCCs contained oligomeric carbohydrate chains (Figures 3 and 4). This conclusion is based on the ratio of non-reducing end units to substituted units as discussed in more detail below.

The main units of the proRL fraction were 4-substituted xylose, 4 and 3-substituted galactose, 4-substituted glucose and 4 and 4,6-substituted mannose in agreement with earlier results (Iversen and Wännström 1986; Minor 1986). Conclusions relating to the linkages in the oligomeric chains were drawn based on the substitution of the monosaccharide units and knowledge of the structure of hemicelluloses. The different chains are schematically presented in Figure 5.

The linkage analysis of galactose units showed also that 3,6-substituted galactose units were present in con- siderable amounts next to a few 6-substituted galactose units. No branching units of 1,4-linked galactan were found.

A more detailed evaluation of the results for the pine pulp samples revealed the presence of 4,6-substituted glucose units in the pine RLCCs. These originated either from branching points in galactoglucomannan or from xyloglucan. Xyloglucan is known to be a component of the primary wall of higher plants and has a backbone of 1,4-linked glucose units, partly branched at position 6 . 2-Substituted xylose units are present in the side chains of xyloglucan (Fry 1989). 2-Substituted xylose units were identified in the pine samples, too. The total content of xyloglucan in pulp is minor, but enrichment in enzymatically-isolated RLCC is possible.

\section{RLCCs of spruce kraft pulp - surface material compared to peeled fiber}

As described in the introduction, the structure of galactans was the focus of the present study. The ratio of 1,4linked galactan and 1,3/6-linked galactan was calculated from 4-substituted galactose units on the one hand, and the sum of 3- and 3,6-substituted galactose units on the other hand (Table 5). About every third galactose unit was branched at position 6 in the 1,3/6-linked galactan in all the proRL fractions of the spruce pulp samples studied. The ratio of 1,4-linked galactan to 1,3/6-linked galactan differed between the proRL fractions and was 0.6 for the SCK1 Fiber, 0.9 for SCK1 and 1.3 for SCK1 Fine. At the same time, the galactose content in the proRL of SCK1 Fine was lower: $1.4 \mathrm{mg} / 100 \mathrm{mg}$ compared to $1.9 \mathrm{mg} /$ $100 \mathrm{mg}$ in both proRL of SCK1 and SCK1 Fiber. It has to be remembered that the proRL fraction of SCK1 Fine represents less of the total lignin than the proRL fractions of SCK1 and SCK1 Fiber (Table 3). Still, the trend of the ratio is clear. The 1,4-linked galactan was thus enriched in the RLCC of the fiber surface, while the share of 1,3/ 6 -linked galactan increased towards the inner part of the fibers. The enrichment of 1,4-linked galactan units in residual lignin of the surface has been reported earlier (Minor 1991). However, the higher amount of 1,3/6-linked galactan in the RLCC of the inner part of the fiber has 

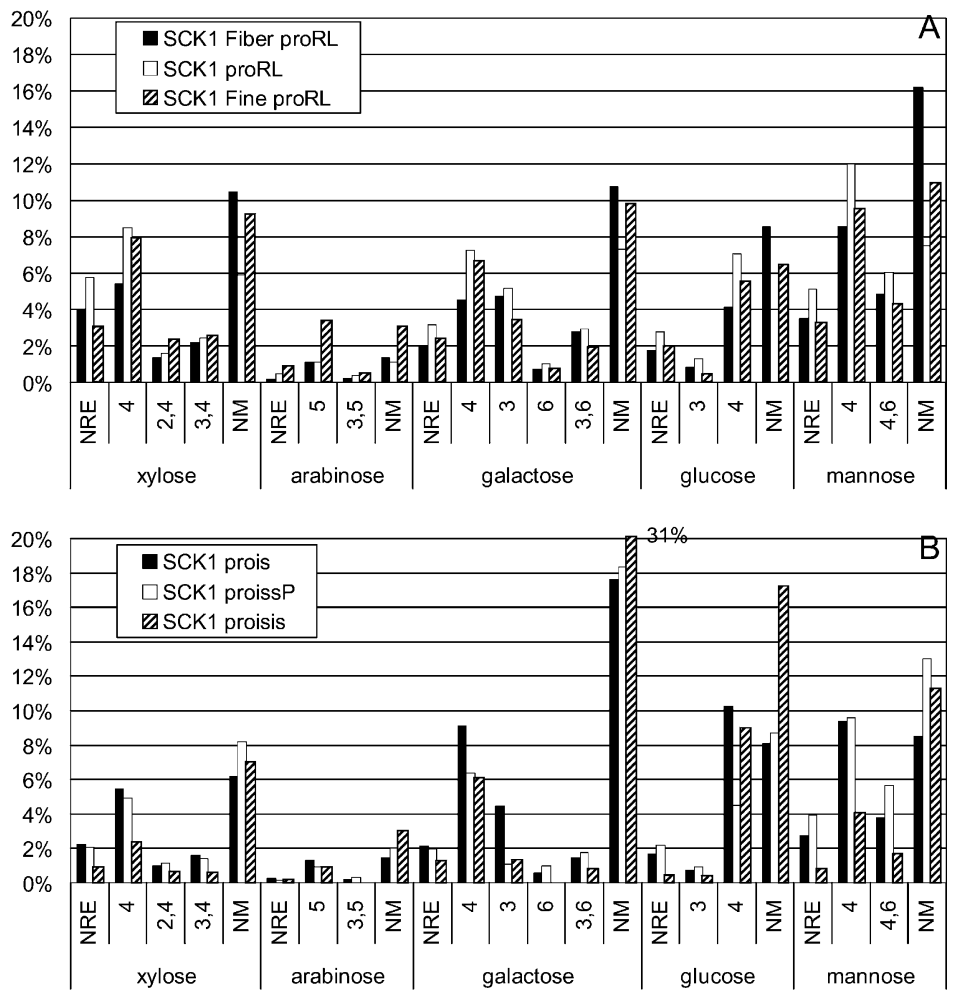

Figures 3 Distribution of substituted carbohydrate structural units in the proRL fractions of the spruce kraft pulp (SCK1), SCK1 Fiber and SCK1 Fine (A) and in the prois sample of SCK1 and its fractions proissP and proisis after further separation. The results are presented as mol\% of the identified units. NRE, non-reducing end; NM, not methylated.

not been shown clearly before. 1,3/6-Linked galactan is known as water-soluble arabinogalactan and is present in small amounts in spruce (Picea abies) and pine (Pinus sylvestris) heartwood (Willför et al. 2002). Its presence in RLCCs indicates that 1,3/6-linked galactan also has a role in linking residual lignin to carbohydrates in the secondary wall. This linkage may be one reason for difficulties in selective lignin removal in bleaching. Improved bleachability has been shown after endo- $\beta-1,4-$ galactanase treatment of unbleached spruce kraft pulp (Tam-
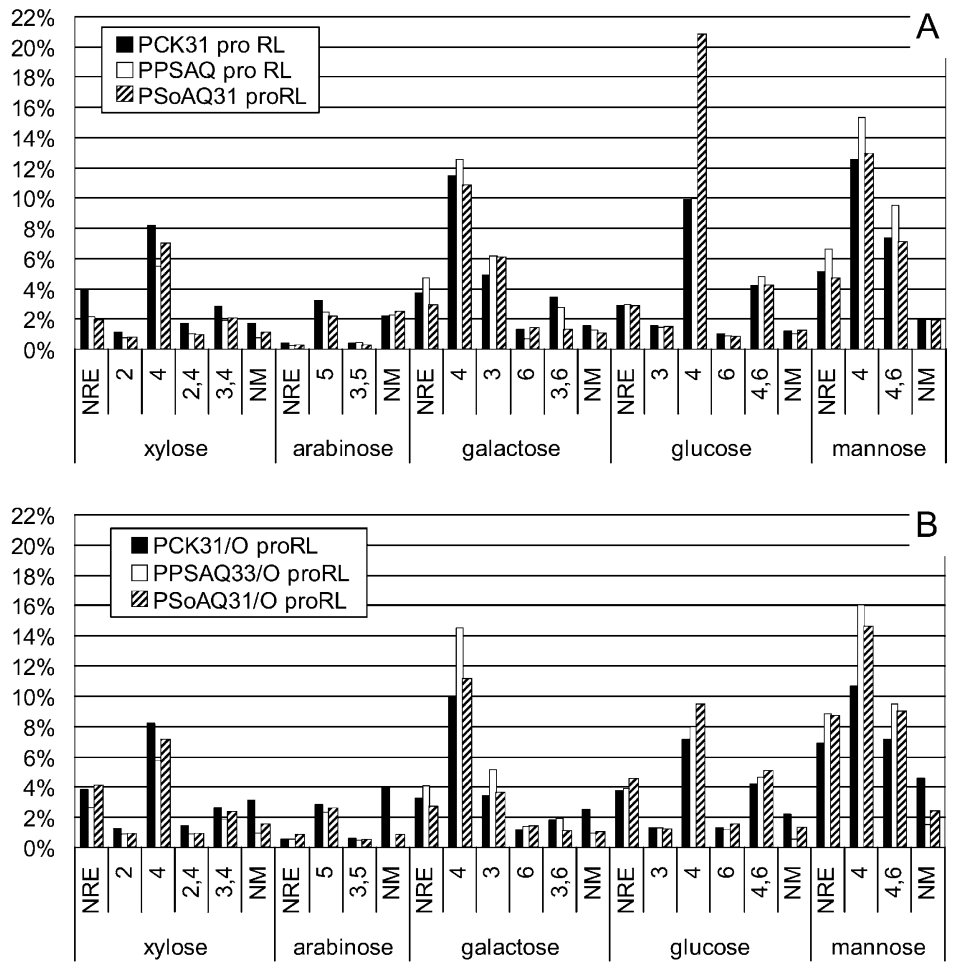

Figure 4 Distribution of substituted carbohydrate structural units in proRL fractions of the unbleached $(A)$ and the oxygen-delignified pine pulps (B). The results are presented as mol\% of the identified units. NRE, non-reducing end; NM, not methylated. 


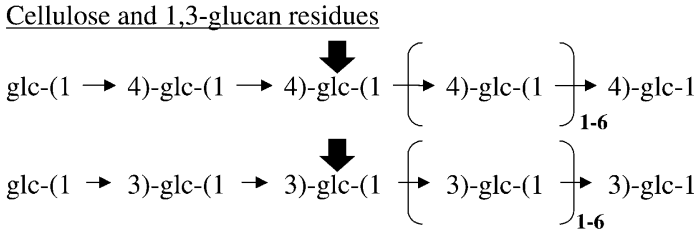

Xylan residues

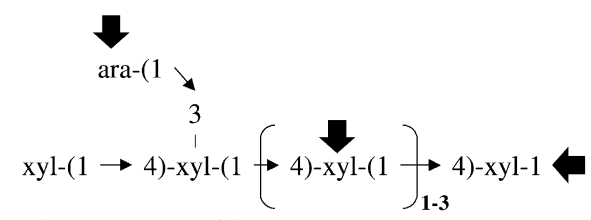

Glucomannan residues

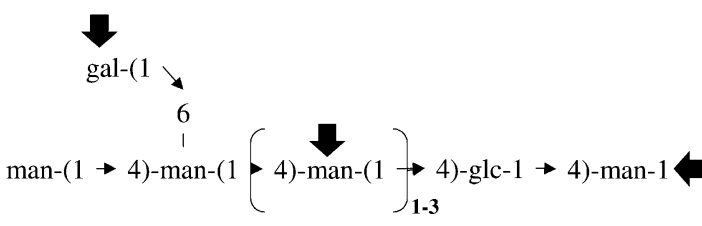

Galactan residues gal-(1 $\rightarrow$ 4)-gal-(1 $\rightarrow$ 4)-gal-(1 $\rightarrow 4)$-gal-(1 $\left.\}_{\mathbf{n}} 4\right)$-gal-1

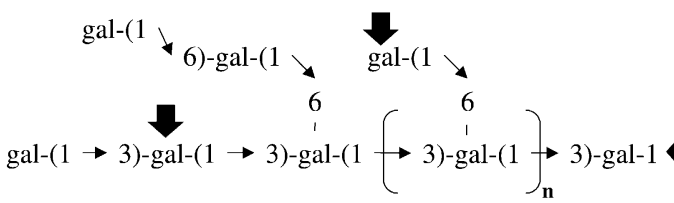

Figure 5 Suggested structures of carbohydrate residues in RLCCs of SCK1 and SCK2. The bold arrows show possible binding sites to lignin.

minen et al. 1999). These positive results could probably be further improved by using an endo- $\beta-1,3$-galactanase simultaneously (Tenkanen et al. 2002). However, such an enzyme has not been found (Luonteri et al. 2003). Arabinose was present mainly as a 5-substituted unit (Figure $3 A)$. This is in agreement with reports in the literature that arabinose is present in enzymatically-isolated lignin mainly in the form of 1,5-linked arabinan and not as side groups in xylan which would be detected as non-reducing end groups (Iversen and Wännström 1986; Minor 1991). Xylose and mannose units were substituted in a way that corresponded to the known structures of xylan and glucomannan. Glucose was present as a 4-substituted unit, and to a small extent also as a 3-substituted unit. Recently, 1,3-linked glucan was found in the effluents from the alkaline stage and the oxygen delignification of pine kraft pulp (Pinus sylvestris; Laine and Tamminen 2002). 1,3-linked glucan is therefore linked in small amounts to the residual lignin.

\section{Sparingly soluble RLCC of spruce pulp}

The RLCC prois fraction of SCK1 was studied in more detail (Figure 3B). The same structural units were found as those in the proRL fractions studied. The ratio of 1,4linked galactan to 1,3/6-linked galactan was higher (1.5) than for the proRL fraction of SCK1 (0.9). It seems that the 1,4-linked galactan is more enriched in the prois fraction. Assuming the same trend for the RLCCs of the SCK1 Fine sample, 1,4-linked galactan would be even more enriched in the RLCCs of the surface material than the analysis of the proRL fraction showed, because a higher share of residual lignin was isolated as the prois fraction for the SCK1 Fine sample compared to the SCK1 and SCK1 Fiber samples (see above).

The sparingly alkali-soluble (proissP) and alkali-insoluble (proisis) fractions of the prois sample of SCK1 were methylated to a lower degree than the original prois sample itself. Surprisingly, fractionation, it appeared, somehow reduced the accessibility of the methylation reagent to the carbohydrate residues. Apparently, the treatment with alkaline solution for the fractionation of the prois fraction had an effect on the accessibility of the oligoand/or polysaccharides in the methylation procedure.

During fractionation, the ratio of 1,4-linked galactan to 1,3/6-linked galactan increased further. One reason might be that there was a larger decrease in reactivity of the 3and 3,6-substituted galactose units towards methylation than there was for the 4-substituted units. It was noted that large numbers of galactose and glucose units remained unmethylated in the analysis of the SCK1 proisis fraction. The presence of cellulose probably explains the increase in 4-substituted units and non-methylated glucose units in the proisis fraction. Still, the major portion of the cellulose probably remained undetected, because of its unreactivity under the conditions applied in the methylation step and subsequent acid methanolysis procedure.

\section{RLCCs of pine pulps - comparison of different alkaline cooking methods}

In the pro RL fractions of the RLCCs of the unbleached pine pulps, the ratio of 1,4- to 1,3/6-linked galactan was slightly higher for PSoAQ compared to PCK and PPSAQ (Table 5). There was a clearer difference in the degree of branching. The proportion of branched units in 1,3/6galactan in the RLCCs increased in the order PSOAQ pulp, PPSAQ pulp and PCK pulp. This indicates that SoAQ cooking, and to a smaller extent PSAQ cooking, removes more side-chains from 1,3/6-galactan than CK cooking. The RLCC of PSoAQ contained more 4-substituted glucose than the corresponding other two RLCCs. This may indicate an enrichment of cellulose bound to the residual lignin in the PSoAQ proRL. A possible explanation for this is the formation of ether-type bonds between glucose and lignin in sulfur-free SoAQ cooking. The enhanced formation of this type of bond has been shown under sulfur-free cooking conditions compared to sulfur-containing cooking methods in model compound studies (Gierer and Wännström 1986). These small differences possibly indicate differences in the linkage of lignin and carbohydrates in the SoAQ pulp that contribute to its poorer bleachability.

Generally, the ratios of 1,4-to 1,3/6-linked galactan were higher than the corresponding values determined for the corresponding RLCC of SCK1 (Table 5). The possible reasons for the differences are the higher kappa of the spruce kraft pulp (36 compared to 30-33), the different wood species or the lower degree of methylation due to the performing of only two methylation cycles for the RLCC of the spruce kraft pulp. The difference in branching of 1,3/6-galactan between RLCCs of SCK1 and PCK 
in turn was smaller than the differences between RLCCs of pulps prepared by different cooking methods.

The ratio of 1,4-to 1,3/6-linked galactan units was higher for the RLCCs of the oxygen-delignified pulps than those of the unbleached pulps. The RLCC of the SoAQ pulp had a higher ratio after oxygen-delignification than the RLCCs of the other two pulps. This indicated that 1,4-galactan remains more closely bound to the residual lignin than did 1,3/6-linked galactan during oxygen delignification, or that relatively more lignin was removed from the secondary wall compared to the primary wall in oxygen delignification. The RLCC of the secondary wall has been shown to be enriched in 1,3/ 6-linked galactan compared with the RLCC of fiber surface material (see above). Consequently, the preferred removal of lignin from the secondary wall would reduce the content of 1,3/6-linked galactan in isolated RLCCs relative to that of 1,4-linked galactan. However, this was not supported by a study on the structure of carbohydrates in oxygen delignification filtrates. In that study no enhanced dissolution of 1,3/6-linked galactan compared to 1,4-linked galactan was observed (Laine and Tamminen 2002). The structure of the 1,3/6-galactan remaining in the RLCCs after oxygen delignification was similar to that in RLCCs of unbleached pulps, as far as the degree of branching and share of non-reducing ends was concerned. The 1,3/6-linked galactan in the PSoAQ/O proRL had the lowest degree of branching which increased in PPSAQ/O proRL and even more in the PCK/O proRL.

\section{Non-reducing ends of carbohydrate chains}

The structural analysis delivered information on the nonreducing ends of the different oligosaccharide chains linked to lignin in the RLCCs. The quantity of non-reducing ends of all methylated units was $14-23$ mol\% (Table 5). This value provides information on the chain length of the oligosaccharide residues. The number of non-reducing ends in the RLCCs closely matched the number of carbohydrate-lignin bonds of the benzylether type reported for residual lignin of spruce kraft pulp (12.5 mol\%; Choi 1999). For the spruce pulp samples, the share was smaller for the prois fraction of SCK1 compared to the corresponding proRL fraction. The values were $15 \mathrm{~mol} \%$ and $23 \mathrm{~mol} \%$, respectively. This probably means that there were shorter oligosaccharide chains in the proRL fraction. For the pine pulp samples, the proportion of non-reducing end units was lower than in SCK1 proRL. The non-reducing ends represented $18 \%$ of the methylated units in PCK proRL and PPSAQ proRL. A lower value of $14 \%$ was observed for the PSoAQ proRL indicating longer chains.

The separate evaluation of non-reducing ends within each monosaccharide showed that the value was clearly lower for xylose and glucose units, slightly lower for galactose in $\mathrm{PSOAQ}$ proRL, but comparable for mannose units compared to PCK and PPSAQ. This meant that the xylan, cellulose and 1,3-glucan residues in particular had on average longer chain lengths in the PSOAQ proRL.

The RLCCs of the oxygen-delignified pulp had a higher proportion of non-reducing ends (21-22\%) indicating that there were shorter oligosaccharide chains attached to the RLCCs of oxygen-delignified pulps compared to
Table 6 Apparent number average degree of polymerization $\left(D_{n}\right)$ for carbohydrate residues in RLCCs of the spruce pulp samples. The calculation is based on either $A$ : ratio of chain units to non-reducing end or on $\mathrm{B}$ : ratio of chain units to reducing ends.

\begin{tabular}{lccccc}
\hline Sample & Based on & Gal & Glu & Xyl & Man \\
\hline proRL of SCK1 & A & & 4 & 3 & 5 \\
proRL of SCK2 & B & $130^{*}$ & 5 & 8 & 10 \\
prois of SCK1 & A & & 8 & 5 & 6 \\
prois of SCK2 & B & $170^{*}$ & 10 & 10 & 14 \\
\hline
\end{tabular}

${ }^{*}$ Exact value $>20$ and therefore unreliable.

For abbreviations of sugars, see legend to Table 2.

those of unbleached pulps. The chains of glucomannan and glucan residues were shorter for the RLCCs of all three pulps. This indicated less steric hindrance for the enzymes used for RLCC isolation in oxygen-delignified pulps compared to unbleached pulps. The chains of xylan residues were significantly shorter for the PSoAQ/ $\mathrm{O}$ proRL only. The chain length of the carbohydrate residues was comparable for cellulose, glucan and glucomannan chains in-between the RLCCs of the oxygen-delignified pulps.

\section{Reducing ends}

The reducing ends were analyzed using sodium borohydride reduction, acid methanolysis and GC/MS determination. The analysis of reducing ends was performed for RLCCs of a new spruce kraft pulp (SCK2) prepared under the same conditions as SCK1. It was assumed that the RLCCs of the new pulp were approximately the same as the RLCCs of SCK1.

The effectiveness of the reduction was tested first. Half of the reduced sample was hydrolyzed directly after the first reduction. The other half of each sample was reduced a second time before acid methanolysis was carried out. The quantity of reduced monosaccharides increased in the second reduction step. The proportion of reducing ends in the proRL sample was $7.6 \mathrm{~mol} \%$ and $9.5 \mathrm{~mol} \%$ after the first and second reduction, respectively. The corresponding values were $4.6 \mathrm{~mol} \%$ and $5.3 \mathrm{~mol} \%$ for the prois sample. The repeated reduction therefore appeared necessary.

\section{Possible lignin-carbohydrate binding sites}

An oligomeric or polymeric chain can be bound to the lignin via the non-reducing end, the reducing end or another backbone unit of the chain. If a chain of a certain structural type (xylan, glucan, glucomannan etc.) is bound only in the middle to lignin, the number of reducing or non-reducing end units would be the same. Based on the ratio of either non-reducing ends to chain units or reducing ends to chain units, the apparent number average degree of polymerization $\left(D_{n}\right)$ was calculated for RLCCs of the spruce kraft pulp (Table 6). Conclusions were drawn on the possible positions of lignin-carbohydrate bonds (Figure 5) as discussed in the following.

For glucose, the $\mathrm{DP}_{\mathrm{n}} \mathrm{s}$ were equal, indicating bonds between a chain unit of cellulose or glucan to lignin. The $\mathrm{DP}_{\mathrm{n}} \mathrm{s}$ were approximately 5 and 10 for the proRL and prois fraction, respectively. 
For xylose, the estimated $\mathrm{DP}_{\mathrm{n}} \mathrm{s}$ differed. A possible reason for this was that the xylo-oligosaccharides were partly bound to the lignin via the reducing end groups. This is supported by the reported formation of bonds between reducing ends of xylo-oligosaccharides and lignin model compounds under kraft pulping conditions (Vikkula et al. 2001). The $D P_{n}$ of xylo-oligosaccharides is estimated to be between 3 and 5 . The situation was similar for the mannose units, but caution should be exercised because some of the mannose originated from the protein.

The proportion of reducing ends of galactose was very small. An estimation of $\mathrm{DP}_{\mathrm{n}}$ based on the share of nonreducing ends could not be carried out because the 1,3linked galactan chains were branched and the non-reducing end groups were therefore positioned to a large extent at the end of side-chains. In addition, the distribution of the non-reducing end groups between the 1,3/6 and 1,4-linked galactan on the one hand, and single unit side-chains of galactoglucomannan on the other hand, was not known.

A report by Minor (1991) also showed a high apparent chain length of galactans in residual lignin from the secondary wall of loblolly pine kraft pulp, based on analysis of reducing end groups. Another study reported approximately equal amounts of galactose as non-reducing and reducing ends in residual lignin from pine kraft pulp (Iversen and Wännström 1986). Iversen and Wännström's study also differed from ours and from that of Minor (1991) in that the presence of any 3-substituted galactose was not reported. The question still remains whether the RLCCs differs due to the isolation method or whether differences in the procedure of the methylation analysis applied give rise to the different results.

The results for galactose in RLCCs in our study can be interpreted as chains consisting of galactose units being rather long due to missing galactanase activity in the enzyme mixture applied, as suggested in the literature (Iversen et al. 1987). The lack of the necessary enzyme for hydrolyzing 1,3-linked galactan (Luonteri et al. 2003) would also support the theory for long chains of 1,3/6linked galactan in RLCCs. A second possibility is that shorter chains of galactose units are connected to lignin at the reducing end. However, even if galactan residues in residual lignin had long chains, numerous bonds to lignin would be expected based on the properties of the RLCCs. This is further supported by a study on the frequency of benzyl ether bonds between carbohydrates and lignin which showed there was a high frequency of bonds between galactose units and residual spruce kraft lignin (Choi and Faix 1999).

The $\mathrm{DP}_{\mathrm{n}}$ for arabinan chains was not estimated. The number of different units of arabinose was so low that the error limits became too high to allow use of the values for further calculation.

\section{Conclusions}

All RLCC investigated contained oligosaccharides of the main polysaccharides in wood and pulp. In addition, 1,4linked and 1,3/6-linked galactans were present in considerable amounts as well as smaller amounts of 1,3-linked glucan and 1,5-linked arabinan, possibly also xyloglucan structures.

The ratio of 1,4-linked and 1,3/6-linked galactan in the RLCC fractions of spruce kraft pulp increased from peeled fibers to pulp to fines. The presence of considerable amounts of 1,3/6-linked galactan in the RLCC of the peeled fiber was shown for the first time. It is suggested that 1,3/6-linked galactan has a role in hindering delignification of the secondary wall.

Methylation was less complete for the prois fractions and especially low for the prois fraction of the fines, which may indicate that lignin partly covers the cellulose fibrils including part of the hemicelluloses, in particular on the fiber surface.

These results combined with those in the literature, indicated that xylan residues were partly bound to lignin via the reducing end groups and that the RLCCs contained either long galactan chains or bonds linking galactans to lignin via the reducing ends.

There were only small differences in the structure of carbohydrates in RLCCs of three unbleached pine pulps. Slightly longer oligosaccharide chains, less branching in 1,3/6-galactan residues and more cellulose residues were found in the RLCC of PSoAQ compared to those of PCK and PPSAQ pulps.

Oxygen delignification shortened the oligosaccharide chains present in RLCCs and removed preferably 1,3/6linked galactan compared to 1,4-linked galactan structures connected to residual lignin. The RLCC of PSoAQ/ $O$ differed from those of the other two pulps after oxygen-delignification in that it had a higher ratio of 1,4- to 1,3/6 linked galactan, and shorter xylan residues.

Even this detailed analysis did not reveal large differences in the PSoAQ pulp that could explain its poor bleaching response. It is possible that factors other than the chemical composition and interactions between lignin and carbohydrates affect the bleachability of the pulps. These factors may be physical rather than chemical.

\section{Acknowledgements}

Part of the work was financed by the Technology Development Centre of Finland (TEKES) (spruce pulp samples) and the EU project "Bleachability of alkaline pulps" (FAIR CT 983460 ) (pine pulp samples). The financial support of the Emil Aaltonen Säätiö, Tampere, Finland is acknowledged. Seija Salo and Markku Oila are thanked for their skillful experimental work.

\section{References}

Argyropoulus, D.S., Sun, Y., Paluš, E. (2002) Isolation of residual lignin in high yield and purity. J. Pulp Pap. Sci. 28:50-54.

Browning, B.L. Methods of wood chemistry. Vol. 2. Interscience Publishers, New York, 1967. pp. 785.

Choi, J.-W. Vergleichende Untersuchung an Restligninen und Lignin-Kohlenhydratkomplexen (LCCs) von diversen Fichtenund Buchenzellstoffen. Dissertation. Hamburg, Germany, 1999.

Choi, J.-W., Faix, O. (1999) Investigation on residual lignins and residual carbohydrates and the covalent bonds between them. In: 10th International symposium on wood and pulping chemistry. Yokohama, Japan. June 7-10. Vol. 1, pp. 368-373. 
Ciucane, I., Kerek, F. (1984) A simple and rapid method for the permethylation of carbohydrates. Carbohydr. Res. 131:209-217.

Eriksson, Ö., Goring, D.A.I., Lindgren, B.O. (1980) Structural studies on chemical bonds between lignins and carbohydrates in spruce wood. Wood Sci. Technol. 14:267-279.

Fry, S.C. (1989) The structure and functions of xyloglucan. J. Exp. Bot. 40:1-11.

Gierer, J., Wännström, S. (1986) Formation of ether bonds between lignin and carbohydrates during alkaline pulping processes. Holzforschung 40:347-352.

Hausalo, T. (1995) Analysis of wood and pulp carbohydrates by anion exchange chromatography with pulsed amperometric detection. In: 8th International symposium on wood and pulping chemistry. Helsinki, Finland. June 6-9. Vol. 3, pp. 131-136.

Hortling, B., Tamminen T. (2001) Isolation of residual lignin by acidolysis and enzymatic hydrolysis: comparison and application of methods. In: 11th International symposium on wood and pulping chemistry. Nice, France. June 11-14. Vol. 1, pp. 235-238.

Hortling, B., Tamminen, T., Ranua, M., Poppius-Levlin, K., Kettunen, H., Niskanen, K. (2000) Influence of cooking method on bleachability and reinforcement power. In: 2000 International pulp bleaching conference. Halifax, Nova Scotia, Canada. June 27-30, pp. 29-35.

Hortling, B., Tamminen, T., Pekkala, O. (2001) Effects of delignification on residual lignin-carbohydrate complexes in normal pine wood and pine wood enriched in compression wood. 1. Kraft pulping. Nord. Pulp Pap. Res. J. 16:219-224.

Iversen, T. (1985) Lignin-carbohydrate bonds in a lignin-carbohydrate complex isolated from spruce. Wood Sci. Technol. 19:243-251.

Iversen, T., Westermark, U. (1985) Lignin-carbohydrate bonds in pine lignins dissolved during kraft pulping. Cell. Chem. Technol. 19:531-536.

Iversen, T., Wännström, S. (1986) Lignin-carbohydrate bonds in a residual lignin isolated from pine kraft pulp. Holzforschung 40:19-22.

Iversen, T., Westermark, U., Samuelsson, B. (1987) Some comments on the isolation of galactose-containing lignin-carbohydrate complexes. Holzforschung 41:119-121.

Jääskeläinen A.-S., Sun, Y., Argyropoulos, D.S., Tamminen, T., Hortling, B. (2003) The effect of isolation method on the chemical structure of residual lignin. Wood Sci. Technol. 37:91-102.

Laine, C., Tamminen, T. (2002) Origin of carbohydrates dissolved during oxygen delignification of birch and pine kraft pulp. Nord. Pulp Pap. Res. J. 17:46-49.

Laine, C., Tamminen, T., Vikkula, A., Vuorinen, T. (2002) Methylation analysis as a tool for structural analysis of wood polysaccharides. Holzforschung 56:607-614.

Li, J., Gellerstedt, G. (1997) The contribution to kappa number from hexeneuronic acid groups in pulp xylan. Carbohydr. Res. 302:213-218.

Liitiä, T., Maunu, S.L., Hortling B. (2000a) Solid-state NMR studies on cellulose crystallinity in fines and bulk fibres separated from refined kraft pulp. Holzforschung 54:618-624.

Liitiä, T., Maunu, S.L., Hortling B. (2000b) Solid-state NMR studies of residual lignin and its association with carbohydrate. J. Pulp Pap. Sci. 26:323-330.

Luonteri, E., Laine, C., Uusitalo, S., Teleman, A., Siika-aho, M., Tenkanen, M. (2003) Purification and characterization of Aspergillus b-D-galactanases acting on b-1,4- and b-1,3/6linked arabinogalactans. Carbohydr. Pol. 53:155-168.

Minor, J.L. (1982) Chemical linkage of pine polysaccharides to lignin. J. Wood Chem. Technol. 2:1-16.
Minor, J.L. (1986) Chemical linkage of polysaccharides to residual lignin in loblolly pine kraft pulps. J. Wood Chem. Technol. 6:185-201.

Minor, J.L. (1991) Location of lignin-bonded pectic polysaccharides. Wood Chem. Technol. 11:159-169.

Scandinavian standard (1977) SCAN-C 1:77. Method for the determination of the Kappa number of pulp (degree of delignification).

Scandinavian standard (1999) SCAN-CM 15:99. Pulps-Viscosity in cupriethylenediamine solution.

Sundberg, A., Sundberg, K., Lillandt, C., Holmbom, B. (1996) Determination of hemicelluloses and pectins in wood and pulp fibres by acid methanolysis and gas chromatography. Nord. Pulp Pap. J. 11:216-220.

Tamminen, T., Hortling, B. (1999) Isolation and characterization of residual lignin. In: Progress in Lignocellulosics Characterization. Ed. Argyropoulos, D.S. Tappi Press, Atlanta. pp. $1-42$.

Tamminen, T. Hortling, B. (2001) Lignin reactions during oxygen delignification of various alkaline pulps. In: Oxidative delignification chemistry. Fundamentals and catalysis. Ed. Argyropoulos, D.S. ACS Symp. Ser. 219, Washington. pp. 73-91.

Tamminen, T., Hortling, B., Ranua, M., Luonteri, E., Suurnäkki, A., Tenkanen M., Buchert, J. (1999) Enhanced bleachability of spruce kraft pulp by mechanical and enzymatic treatments. In: 10th International symposium on wood and pulping chemistry. Yokohama, Japan. June 7-10. Vol. 1, pp. 584-588.

Tenkanen, M., Hausalo, T., Siika-aho, M., Buchert, J., Viikari, L. (1995) Use of enzymes in combination with anion exchange chromatography in the analysis of carbohydrate composition of kraft pulps. In: 8th International symposium on wood and pulping chemistry. Helsinki, Finland. June $6-9$, Vol. 3, pp.189-195.

Tenkanen, M., Luonteri, E., Suurnäkki, A., Ranua, M., Tamminen, T., Hortling, B. (2002) b-D-galactanases acting on b-1,4 and b1,3/6-linked arabinogalactans in kraft pulp. In: Workshop COST E23 "Biotechnology for improving pulp and paper processing". Grenoble, France. Nov 28-29. 8 pages.

Vikkula A., Hortling, B., Tamminen, T., Teleman, A., Tenkanen, M., Vuorinen, T. (1997) Structure of galactans in kraft cooking liquors. In: 9th International Symposium on Wood and Pulping Chemistry. Montreal, Canada. June 9-12. Vol. 2, pp. 1171-3.

Vikkula A., Letumier, F., Tenkanen, M., Sipila, J., T. Vuorinen, (2001) Generation of phenol-xylan complexes in kraft pulping conditions. In: 11th International symposium on wood and pulping chemistry. Nice, France. June 11-14. Vol. 1, pp. 51-54.

Watanabe, T. (1989) Structural studies on the covalent bonds between lignin and carbohydrate in lignin-carbohydrate complexes by selective oxidation of the lignin with 2,3-dichloro5,6-dicyano-1,4-benzoquinone. Wood Res. 76:59-123.

Willför, S., Sjöholm, R., Laine, C., Holmbom, B. (2002) Structural features of water-soluble arabinogalactans from Norway spruce and Scots pine heartwood. Wood Sci. Technol. 36:101-110

Willför, S., Sjöholm, R., Laine, C., Roslund, M., Hemming, J., Holmbom, B. (2003) Characterisation of water-soluble galactoglucomannans from Norway spruce wood and thermomechanical pulp. Carbohydr. Pol. 52:175-187.

Yamasaki, T., Hosoya, S., Chen, C.-L., Gratzl, J.S., Chang, H.m. (1981) Characterization of residual lignin in kraft pulp. In: 1st International symposium on wood and pulping chemistry. Stockholm, Sweden. June 9-12. Vol. 2, pp. 34-42.

Received September 29, 2003 